\title{
Museos y conflicto; la representación de la guerra en la museografía colombiana
}

\author{
Carlos Arturo Rojas Pérez \\ Instituto de Investigaciones Estéticas / Universidad Nacional de Colombia
}

En tiempos de supuesto posconflicto es necesario evaluar, de manera crítica, las representaciones de la violencia en el museo colombiano. Este artículo pretende hacer un breve paneo por algunos casos que narran la violencia desde lo institucional o desde fuera de las instituciones nacionales y que se sitúan temporalmente en la época de la violencia o que ya apuntan a los tiempos imaginarios ver la guerra en el pasado.

Palabras Clave: violencia, museo, museología colombiana, museografía, posconflicto.

In times of assumption post-conflict need to be assessed critically, depictions of violence in Colombian museum. This article aims to briefly panning by narrating some cases violence from the institutional or outside national institutions and temporarily placed at the time of violence or already point to see the war imaginary times in the past.

Key words: violence, museum, colombian museology, museography, post-conflict.

Los acontecimientos que rodean la historia de un país de antecedentes violentos, como Colombia, nos plantea la problemática de la relación museo-conflicto en cuanto a la posibilidad de soluciones que el museo, y la museología, pueden dar para asimilar y superar, incluso olvidar, dicho pasado violento ${ }^{1}$. En este sentido ¿Cómo estamos resolviendo esta relación en Colombia? ¿Qué hemos hecho y qué nos falta por hacer? ¿Hacia dónde puede apuntar la museología para resolver las problemáticas de un posible posconflicto?

Las anteriores preguntas puede que no queden resueltas con el presente escrito, pero arrojaremos algunas bengalas para que sean seguidas con mayor profundidad, bengalas que pueden iluminar un camino que ya otros habrán intentado dilucidar. En esta intención se usará una metodología simple, la de traer a colación algunos ejemplos de exposiciones que han tocado temas del conflicto armado, y que han intentado explicarlo. Trataremos tres casos específicos: la exposición iBasta Ya!, sobre el Informe de la Comisión de Memoria Histórica (Realizada en el Claustro de San Agustín, edificio colonial administrado por la Universidad Nacional de Colombia ubicado en el centro histórico de Bogotá, en octubre del 2013), el Museo Histórico de la Policía Nacional y el Museo Militar, también en el centro histórico, los cuales, a su manera, tienen un método para explicar esta problemática. La primera como parte de una reflexión académica y artística y los últimos como una reflexión institucional y vocacional. Lo anterior será cotejado con algunos conceptos históricos de

1 Entendiendo que Colombia no es el único país violento del mundo, y ni siquiera es el más violento, pero que en el imaginario común se percibe como tal, percepción que se alimenta desde los medios, la política e incluso la academia. 
la museología que intentan definir el papel del museo en la sociedad, sus limitantes y sus potencias, por último intentaremos hacer una reflexión sobre cómo dichos casos han aspirado a resolver el problema.

\section{Un nuevo contexto para la violencia, ¿posconflicto en Colombia?}

El 18 de octubre de 2012 un gran halo de esperanza recorre el país, de nuevo las FARC y el gobierno, esta vez encabezado por el pupilo renegado de Álvaro Uribe Vélez, Juan Manuel Santos, inician diálogos de paz. Dicho halo de esperanza se transforma rápidamente en un nuevo aire en la academia, que si bien ya estaba curtida en los estudios de la violentología, ve de nuevo la posibilidad de estudiar el conflicto armado a través de la mirada retrospectiva. Esta noticia completaba una especie de círculo que se había empezado a armar con los marcos jurídicos por Uribe, en negociaciones previas con los paramilitares, para la desmovilización de las Autodefensas Unidas de Colombia. Lo que se conoció como la Ley de Justicia y Paz, daba por finalizada, aparentemente, la historia violenta de los grupos que habían aterrorizado varias zonas del país desde finales de los 80 . En ese contexto se centraba la Comisión de Memoria Histórica, grupo de investigadores liderado por Gonzalo Sánchez y con la financiación de la Presidencia de la República, para el esclarecimiento de los pormenores del conflicto y saldar así la deuda del país con su memoria histórica. Como resultado final de dicha investigación la Comisión de Memoria Histórica hizo entrega oficial, en el año 2013, del informe del arduo y juicioso trabajo de investigación. El texto relataba una violencia con raíces en la primera mitad del siglo XX. El texto, titulado iBasta Ya!, Colombia: Memorias de Guerra y Dignidad, rápidamente se estableció, merecidamente, en el sitial de honor de la violentología, formando una trilogía junto con el trabajo de Guzmán, Fals Borda y Umaña Luna La Violencia en Colombia, de 1960 y Colombia: Violencia y Democracia, que el mismo Sánchez había liderado en 1987.

Pese a la admirable investigación, el informe muestra cómo, una vez más, la academia caía en la trampa oficial de pensar que el conflicto armado había finalizado. Esto había sucedido con el estudio de Fals Borda, Guzmán y Umaña Luna, el cual fue duramente criticado en el congreso y reducido en su importancia, mientras la violencia, mutaba e iniciaba una nueva etapa puesto que el Frente Nacional sirvió para apaciguar los ánimos de un país dividido tras la dictadura de Rojas Pinilla pero que.solo profundizó la segregación de la izquierda hasta que esta en su radicalización, de manera inevitablemente, tomó las armas como método de supervivencia y como única opción política.

Por otro lado, los procesos de Justicia y Paz del gobierno de Álvaro Uribe dejaron sin cabezas a las organizaciones paramilitares que se atomizaron en las Ilamadas Bandas Criminales (Bacrim, grupos como los Urabeños, los Rastrojos, las Águilas Negras, etc.) con vocación extorsiva y narcotraficante y sin ideología política, el fantasma de los paramilitares se extinguía a los ojos del establecimiento pero no en la realidad. Sin embargo, pese a los antecedentes, la academia colombiana se situaba en el posconflicto para realizar sus estudios sin prever que al no ser resueltas las verdaderas causas de la violencia (desigualdad, inequitativa distribución de la tierra, cooptación monopólica del poder, etc.) el conflicto solo cambiaría y se transformaría, siempre evolucionando en crueldad.

Pese a ello, en medio de marcos jurídicos para la restitución de tierras e incluso para la paz, que caminaba en paralelo a los diálogos con las FARC y para hacer aún más público el ya difundido evento de entrega del informe iBasta Ya!², se planteó una exposición que resumiría la parte gráfica (fotografias) de dicho trabajo.

2 Vale la pena aclarar que la difusión del evento de entrega fue más grande que el número de colombianos que pudo llegar a leerlo. 


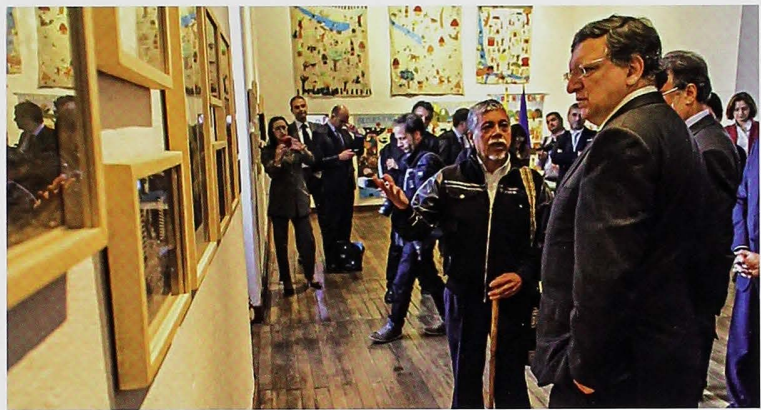

Exposición iBasta ya!, aparece el Profesor Moncayo, explicándole al presidente de la Unión Europa la muestra. Moncayo ha sido reconocido mediáticamente por liderar varios movimientos de víctimas de secuestro de las FARC luego de tener a su hijo secuestrado por más de una década a manos de esta guerrilla. Fuente: http://www.centrodememoriahistorica.gov.co/

\section{iBasta ya!}

La muestra que se anunciaba como un "nuevo grito para que cese el conflicto", estaba dividida en tres partes que se traducían claramente en lo espacial. El salón se seccionaba a través de unos sólidos muros que dejaban tres recuadros que se recorrían de manera "lineal" de inicio a fin. La primera zona, denominada "El Horror", exhibió las fotografías de los antecedentes de la violencia, presentadas de manera limpia en marcos de madera no tratada, en las cuales no podía faltar Gaitán. Según la exposición, la violencia que narraba era la que iba desde 1958 a 2012, un extenso periodo de horror contado por dolorosas imágenes. La segunda parte, titulada "Los daños, el sufrimiento y el dolor", mostraba los estragos de la violencia, filas interminables de féretros, pueblos destrozados y campesinos con miradas llenas de dolor. Por último estaba el tema esperanzador y más reflexivo de la exposición; "Dignidad, resistencia e iniciativas de memoria", espacio dedicado a las iniciativas populares, desde las víctimas, que buscaban reivindicación, justicia, o solo el derecho a la memoria. Este espacio resaltaba por la fuerte presencia de audiovisuales y de los ya famosos Tapices de Mampujan. A esto se añadía un espacio extra, que se encontraba a la entrada del Claustro, denominado "Mil propuestas para la no repetición" en el cual los visitantes aportaban sus ideas para el fin de la violencia, mientras que en paralelo se podía leer en un televisor las propuestas escritas por anteriores visitantes a la muestra.

\section{La Policía y el museo}

La problemática de la violencia también es la piedra angular de la ideología de las fuerzas militares, quienes se han posicionado como los defensores de la institucionalidad, la de turno, frente a las fuerzas que pretenden desestabilizar el supuesto orden. Y así como las naciones modernas tenían sus templos ideológicos en el siglo XIX (congresos, parlamentos), estas fuerzas del orden constituyeron sus templos identitarios a través de museos que recordaban su papel en la historia nacional y en el conflicto, todo bajo el amparo de una idea, la lucha del bien contra el mal.

El primer ejemplo, y el más lejano en el tiempo es el Museo Histórico de la Policía Nacional de Colombia, fundado en 1959, en un ambiente de cambio político. Era el primer año de establecimiento del Frente Nacional, a la cabeza de Lleras Camargo, la clase política creía 


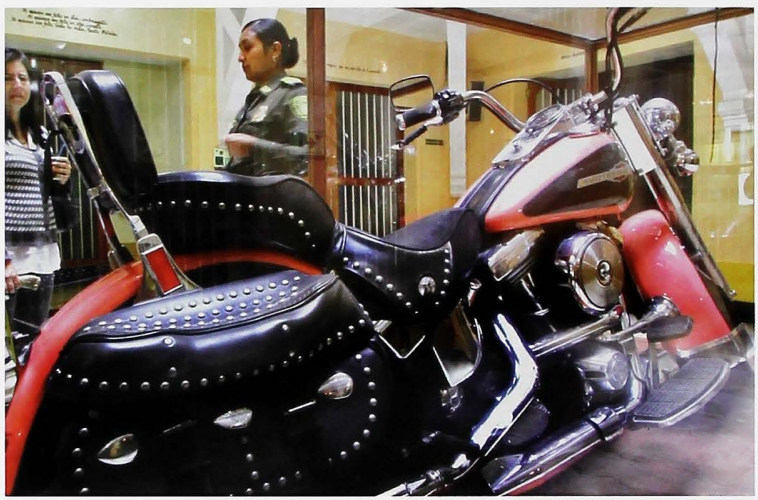

Moto de Pablo Escobar en el Museo Histórico de la Policía Nacional. Fotografía del autor

exorcizar el demonio de la violencia y enterraba la dictadura de Rojas Pinilla la cual había logrado aterrorizar a las elites políticas del conservadurismo y el liberalismo al excluirlos del poder. El Museo, en este sentido, hace parte de ese esfuerzo de enterrar la violencia, de ver el oscuro pasado como un referente superado. Es interesante ver que es en este contexto en el que el estudio de La Violencia en Colombia demostraba claramente el papel de la policía como una fuerza política al servicio del gobierno conservador, su asociación con los chulavitas, innegable en la investigación, fue un escándalo en la época en que fue publicado. En el senado el libro fue tildado de fantasioso e injurioso (Henderson, 1984). Se podría interpretar en este sentido el museo como un esfuerzo para limpiar el nombre de la policía, e iniciar un proceso de cohesión social a través de la identificación nacional con una institución totalmente partidista.

El Museo, ubicado en un lujoso inmueble del centro histórico de la ciudad, construido en los años 20, está constituido por una extensa colección de objetos en su mayoría provenientes del Museo Nacional. Está dividido en 5 plantas, cada una con cuatro o cinco salas de exposición nombradas como algunos generales y personajes ilustres de la historia de la policía. La estructura no corresponde a una cronología clara o a una división temática evidente, sino al organigrama mismo de la institución; es decir las salas están ordenadas por escuelas, divisiones o direcciones, incluso en el primer piso se encuentra un oratorio en el que se recuerdan "las tradiciones religiosas inherentes al policía"3.

Lo anterior no quiere decir que no hayan alegorías a un origen, casi natural, de la necesidad de la policía, y más que a la policía como tal, es a la historia de las armas a lo que se consagra el museo, desde las armas de los primeros humanos de la prehistoria, representadas por un terrible oleo gigantesco, hasta los más modernos equipos bélicos, todo

3 Museo Histórico de la Policía Nacional de Colombia. Ministerio de la Defensa, República de Colombia. Url: http://www.policia.gov.co/portal/page/portal/MUSEO/Home_Museo, Consultado: 27 de abril de 2014. 
catalogado a imitación de los museos de biología o antropología. Siente el visitante estar viendo una especie de taxonomía detallada de las armas.

Para el visitante "común" no parece ser un museo aburrido, ya que las salas intentan mostrar a través de la contextualización de los objetos; el fascinante mundo de la milicia, tomado como positivo en una sociedad con muchos adeptos a los arquetipos cinematográficos como Rambo, Terminator, Matrix, etc. Una cabeza de caballo le da sentido a la indumentaria del policía carabinero en la sala de dicha escuela; una jungla espesa rodea a un maniquí equipado con el uniforme de los igualmente llamados comandos jungla; el levantamiento de un cadáver es hecho por otro maniquí y acompañado por una gigantografia de una escena del crimen bastante explícita. En otra sala una gigantografía ambientada simula la parte inferior de un helicóptero con algunos "hombres" armados descendiendo con el sonido de las hélices y un ventilador agitando unas hojas sintéticas, con lo cual la contextualización parece completa. Los objetos son escenificados de manera dramática al mejor estilo de Charles Wilson Peale (Morales, 1999: 229-230).

Sin embargo lo más interesante del museo es el trato que se le da al otro, a la antítesis de la mitología policiaca; al criminal. Gran parte del museo está dedicado al crimen, a su historia, a sus excentricidades y sobre todo a su derrota. Una de las salas en las que se exponen las grandes capturas de la Policía, como logros, están los rostros de los grandes "criminales" de la historia reciente; Don Mario, Cuchillo, El Mono Jojoy, Raúl Reyes, los líderes del cartel de los Ochoa, etc. Incluso aparece la fotografía del profesor Beltrán, docente del departamento de Sociología de la Universidad Nacional, quien estuvo detenido por sus presuntos vínculos con las FARC pero fue absuelto por la justicia ${ }^{4}$. Los "criminales y terroristas" aparecen derrotados, con fotos explícitas de sus cadáveres y caras sonrientes de policías heroicos. Pero un personaje tiene un papel principal, "El Capo de capos"; Pablo Escobar, a quien se le dedica toda una sala, en la cual se exhibe la chaqueta con la que fue dado de baja, algunas de sus excéntricas armas, una mesa con una "caleta" o escondite, entre otros objetos personales que recuerdan el momento en que fue abaleado por personal de la policía $a^{5}$ Más que eso llama la atención que el museo mismo tiene en su centro, en el sótano, visible desde todos los pasillos de las plantas superiores, una motocicleta Harley Davidson roja, propiedad de Escobar, en una vitrina de vidrio casi como la pieza principal de la institución.

Lo anterior nos permite concluir que la idea de la lucha contra el mal desde el bien, desde la institución, es la idea principal del museo y el mensaje que se intenta reforzar en todas las salas, esto a pesar que en la exhibición del ese otro, el enemigo, parezca incluso apologética aunque la intención sea solo demostrar su desenfreno, descontrol y excentricidad. En la propuesta museográfica el conflicto armado es simplificado como una dicotomía.

Otro aspecto que llama la atención es la visita misma al museo, la cual se convierte en toda una experiencia policial, ya que el ingreso al museo, que es gratuito, solo se puede hacer acompañado de un uniformado que hace las veces de guía (¿o guardia?), una vez iniciado el recorrido por las salas, que el guía escoge, ningún visitante puede separase del grupo incluso si el usuario desea dar por terminado el recorrido (en última instancia se llama a otro policía que acompaña al desertor visitante hasta la salida). En cada sala el guía pide

4 Durante la visita tuve la oportunidad de interpelar a la guía, una uniformada, sobre las razones por las cuales Beltrán continuara estando en el mismo muro con narcotraficantes, paramilitares o guerrilleros, a lo cual la guía contesto, con bastante enojo, que esa sala estaba dedicada las capturas y el profesor había sido capturado. A la fecha está pendiente un proceso por parte de la Procuraduría General de la Nación quien reabrió el proceso desde lo disciplinario aunque esté cerrado desde lo penal.

5 Poco o nada se dice de la colaboración de los Hermanos Orejuela en la localización y captura de Escobar a través de sofisticadísimos equipos de interceptación telefónica a los que solo tenían acceso los líderes del Cartel de Cali. 
la atención de su público, censurando a quienes se dedican a ver los objetos e ignoran la explicación. Una vez finalizada su interpretación autoriza unos segundos para que vean los objetos de la exhibición y se realice alguna pregunta.

\section{Museo militar}

En este mismo orden de ideas, y de mensaje, se encuentra el Museo Militar, dedicado a resaltar la historia de las fuerzas armadas militares del país. El museo se encuentra igualmente en el centro histórico de Bogotá, en un edificio diseñado por el Ingeniero Borda Tanco en la primera década del siglo XX, el estilo ornamental de su fachada que combina el art deco y el art nouveau, albergó originalmente, la Escuela de Ingeniería de la Universidad Nacional. En comparación con el Museo Histórico de la Policía Nacional, el del ejército es mucho más cercano en cuanto a su fundación la cual se da en 1982. Primero llamado Museo de Armas y alimentado por una extensa colección de armas, uniformes e incluso aviones y helicópteros, su colección matriz proviene de la Escuela Militar de Cadetes.

La idea maniquea de la lucha del bien y el mal está igualmente presente y es el mensaje principal que se intenta transmitir en el recorrido, reforzado con la mitología militar del nacimiento del Ejército Nacional en la Batalla de Boyacá en 1819, desde donde se remonta al ejército como defensor de la nacionalidad colombiana, primero contra el invasor español y luego contra el enemigo terrorista.

La visita es mucho más libre, al no haber guías el usuario puede recorrer la edificación a su antojo, no están prohibidas las fotografías y no hay una vigilancia permanente sobre el visitante, excepto por el circuito cerrado de cámaras.

La taxonomía de las armas se vuelve a hacer presente, al igual que el orgullo que representa el uniforme y su evolución, hay varios videos que recuerdan las victorias del ejército ya sea contra los españoles o contra las guerrillas. Obviamente no se habla de las derrotas del ejército, y poco o nada se dice de los conflictos internos nacionales del siglo XIX y el papel que pudo haber tenido el ejército, o los ejércitos, al servicio de los supremos señores regionales. Es fuerte la idea del nacimiento del ejército junto con el país como república independiente, esa idea falsa de continuidad le da al ejército, a través del museo y su museografía, legitimidad nacional histórica.

En resumen los dos museos hacen parte de un modelo de simplificación del conflicto armado como una dicotomía de buenos y malos. Son museos generalmente alejados de la academia, que no aceptan cuestionamientos ni interpelan acontecimientos históricos dados de la llegada de la Nueva Historia ${ }^{6}$ al país. Es la historia típica del modelo de la Academia Colombiana de Historia, donde lo que importa son las fechas y los nombres y no las interpretaciones que se puedan hacer de los sucesos históricos ni mucho menos de las formas de entender o explicar el conflicto armado. La experiencia es diametralmente opuesta frente al ejemplo del iBasta ya!, el cual representa las reflexiones que desde el arte y la academia se hacen del conflicto, donde la idea de buenos y malos no aparece de manera evidente pero sí es recalcitrante la idea de víctima y victimario.

\section{Discusión conceptual}

Ya explorados de manera rápida los anteriores ejemplos podemos proceder a intentar asociarlos a través de algunos conceptos que establece la museología, para buscar las relaciones y rupturas con las anteriores formas de presentar el conflicto.

6 Como "Nueva Historia" se denominó a una nueva corriente de la diciplina histórica que nació desde la Universidad Nacional de Colombia con la fundación del Anuario Colombiano de Historia Social y de la Cultura en dicha universidad. Junto a su fundador, Jaime Jaramillo Uribe, se alinearon historiadores que replantearon la historia nacional y latinoamericana bajo la lupa del materialismo histórico, la historia de las ideas, la historia social y la historia cultural. 
Es normal, e incluso aburrido, que se recurra a definir el museo antes de hablar de una problemática del mismo, a lo cual recurriremos ahora. Sin embargo este escrito tiene el objetivo de especificar el papel del museo en la explicación de la violencia y cómo los anteriores casos intentan resolver el problema desde su posición de institución museal.

A finales del siglo XIX, el padre del Smithsonian definía al museo como:

" $a$ institution for the preservation of those objects which best illustrate the phenomena of nature and the works of man, and the utilization of these for the increase of knowledge and for the culture enlightenment of the people" (Brown Goode, 1895: 122).

En dicha definición el Museo Militar y el de la Policía parecen entrar cabalmente, tienen unos objetos que ilustran y pretenden "iluminar" a la gente sobre un conocimiento, sin embargo más que conocimiento es la idea de que en el conflicto colombiano hay buenos y hay malos, generalmente los últimos son derrotados por los primeros. Sin embargo la definición de Brown Goode tiene una palabra más profunda, siempre asociada al museo "institution", ¿Qué es una institución? Deloche nos ayuda a puntualizar: "manera convencional de organizar la socialización de una necesidad o de una función" (Deloche, 2002: 99). Y en seguida se pregunta ¿Qué necesidad satisface el museo? A lo que responde que la necesidad de "acumular y conservar" no es suficiente para un museo, sino que éste tiene una necesidad intuitiva, una necesidad de satisfacer los sentidos. Los tres casos expuestos parecen satisfacer esa necesidad, en especial la de ver, sin embargo el "no tocar" está presente en los tres. Pero la necesidad más grande que la exposición y los dos museos subsana es la una especie de reconstrucción de la idea de la nación a partir de las ruinas de la misma, del conflicto como argumento de cohesión, una idea que Déotte expone muy bien en el caso europeo y su relación con la ruina (Déotte, 1994). Este proceso de olvido activo -como lo denomina Déotte- se complementa con la concepción de una Colombia unida contra el crimen, y no de una nación sin coherencia ideológica desde su fundación.

Volviendo a las definiciones, la más convencional, y la más fácilmente citada, es la del ICOM que recita: "Un museo es una institución permanente, sin fines de lucro, al servicio de la sociedad y abierta al público, que adquiere, conserva, estudia, expone y difunde el patrimonio material e inmaterial de la humanidad con fines de estudio, educación y recreo." (ICOM, 2007). Una vez más los casos del Museo Militar y el de la Policía cumplen las condiciones, sin embargo la exposición del iBasta ya! nos plantea una pregunta ¿Es la violencia patrimonio inmaterial de los colombianos? ¿Es la ruina de Bojaya y El Salado patrimonio nacional? Los más optimistas dirían que lo que es patrimonio son las prácticas de resistencia y reivindicación que tanto son nombradas en la exposición. Pero la idea de olvido, no pasivo sino activo -volviendo a Deótte- de esas tragedias de la violencia, que se nos hacen presente como ruina, como tumba, como fotografía de muerte o como cifra, sean superadas pero no olvidadas. El museo intenta, en Colombia, ser parte de este proceso al aislar objetos, fotos, testimonios y recuerdos de su espacio, despojarlos de destino, para hacerlos parte de una construcción de nación en el presente (Deótte. 1994: 32).

En el campo de las definiciones parece que ninguna plantea problemas a los casos expuestos, incluso la funcionalidad decimonónica de entretenimiento racional que John Edward Gray y Brown Goode le otorgan al museo parecen claras (Lucas, 1908: 58). Así mismo se cumple con la condición del museo como una "educational institution on a large scale" (Lucas, 1908: 58). Sin embargo al avanzar más en la historia de los conceptos sobre el museo se puede problematizar el papel que estos dos museos y la exposición iBasta ya! juega en la interpretación del conflicto.

Ya desde finales del siglo XIX se planteaba la idea de una multiplicidad de formas para aprender, si bien no se cuestionaba la linealidad del proceso cognitivo, sí se aceptaba que se podía 
aprender desde una infinita variedad de fuentes (Greenwood, 1893: 187), y que ese conocimiento, que el visitante (hombre del común y no un personaje ilustrado) obtenía en el museo lo hacía ver el mundo de otra manera. Incluso adquiría una especie de ansia "craving" por el conocimiento, que sea dicho se plantea como natural (Greenwood, 1893: 188). En este sentido, haciendo un salto gigantesco en el tiempo, hasta el año 2000 con el modelo contextual de Falk y Dierking (2000), podemos ver que la idea de que el mensaje que transmite un museo debe tener en cuenta varios aspectos parece estar siempre presente. Es claro que cuando ambos autores plantean el modelo contextual están haciendo visible una problemática en el sentido de reconstruir la idea en que se entiende el proceso cognitivo mismo, y no de una simple variedad de recursos o fuentes. Detengámonos en el modelo contextual para examinar los ejemplos a la luz de los ocho elementos que proponen Falk y Dierking.

Las tres muestras traídas a colación tienen algunos de estos conceptos claros, las tres muestras juegan con la motivación y la expectativa de los visitantes, ya que el conflicto es un tema que parece ser identificado por los colombianos sea cual sea el papel que en se encuentre. Puede que el Museo Militar y el de la Policía atraigan más a sus visitantes por la extraña motivación de tener cercanía a los materiales bélicos, pero la exposición iBasta ya! también juega con el sentimiento, a veces morboso, de conocer los pormenores de la violencia.

La idea de nación, como comunidad laica moderna, es sin ninguna duda una creencia, que aglomera a una agrupación de sujetos en una comunidad imaginada, como lo definió Benedic Anderson. Bajo esta creencia, y siguiendo el modelo de Falk y Dierking (2000), los museos y la exposición hacen cercano al visitante al conflicto, en cuanto a que la violencia es un elemento que nos construye como nación, y aunque la idea es vista desde un supuesto pasado, la verdad es que hay identificación porque la violencia aún está presente.

En cuanto a la inmersión en el grupo socio-cultural "Within-group sociocultural mediation" los casos citados sí se quedan cortos puesto que ninguna juega con niveles de lectura, por el contrario, la violencia se aborda desde un lenguaje poco pedagógico o diferenciador entre tipos de espectadores. No parece ser el objetivo de la exposición iBasta Ya! interpelar a un público infantil sobre el tema, y los museos militar y de la policía parecen concentrarse en un público infantil piense en profesionalizarse como un factor armado institucional y no como un solucionador de conflictos

La organización y la orientación, otro de los elementos que Falk y Dierking tienen en cuenta, no sobresalen, y junto con el diseño, no dicen mucho. En los tres ejemplos no hay ningún tipo de experiencia sorpresiva o chocante en términos de recorrido, son recorridos lineales e incluso predecibles. Tal vez el museo de la policía y sus intentos de escenografia son resaltables pero las soluciones gráficas son pésimas. Extraña que en el caso de iBasta ya! No haya nada novedoso en cuanto al diseño y la experiencia misma de la exposición, aunque en el equipo que trabajó la muestra fue un grupo interdisciplinar de arquitectos y artistas plásticos, tal vez hizo falta la asesoría de un museólogo o un pedagogo. En cuanto al Museo de la Policía y el Museo Militar se nota mayor esfuerzo por sorprender, pero como he puntualizado, la realización en términos de diseño museográfico y de montaje se quedan cortos.

La exposición iBasta ya!, como ya se mencionó, tenía una sección anexa a la muestra, en la entrada del Claustro de San Agustín, en la que los visitantes dejaban sus sugerencias para que el conflicto no se repitiera. Este era un esfuerzo loable para que el punto de "refuerzo de eventos y experiencias fuera del museo" (Falk y Dierking, 2000), estuviera presente como complemento a la exposición, sin embargo una vez el visitante escribía su comentario no se llevaba nada, y aunque se implementó una agenda paralela a la exposición con talleres y conferencias, logró poco impacto en una comunidad que nunca apareció definida en los objetivos de la exposición. Por su parte en el Museo Militar o el de la Policía, no hay ningún indicio de programa o de material que trascienda el museo más allá de las páginas web. 


\section{Educación y la posmodernidad}

El Museo Histórico de la Policía Nacional, y el Museo Militar, pese a haber sido fundados en tiempos diferentes, hacen parte de una paradigma de museo del siglo XIX, donde la colección y los objetos son lo más relevantes y constituyen su naturaleza misma. Poco interés denotan, o por lo menos es lo que se siente al recorrerlos, en los públicos que los visitan.

Hooper-Greenhill (2007), establece en su escrito sobre la educación y la posmodernidad cómo el modelo educativo y la concepción del yo cambian desde el modelo moderno al modelo posmoderno en relación con el paradigma del conocimiento. Según Greenhill, en la modernidad el conocimiento se considera un proceso arduo, acumulativo, que está ligado a la racionalidad del ser humano, un proceso lineal que debe ser ordenado para ser asimilado, y que está completamente alejado de los procesos emocionales. Con los cuestionamientos que se hacen en la posmodernidad, y que tienen fuertes cimientos en los nuevos enfoques de la antropología, la sociología y el psicoanálisis, el conocimiento se empieza a ver como un proceso más complejo, que no es controlable ni en tiempo ni espacio y que está ligado fuertemente a la emocionalidad del sujeto. Esto se expresa en la nueva concepción que el cuerpo empieza a tener, generando más importancia a la agrupación de experiencias a través de la totalidad de los sentidos que solo al proceso racional de la mirada dirigida, paradigma de los museos del siglo XIX y comienzos del XX.

Esta transformación del yo, como paso del individuo al sujeto en términos del psicoanálisis, está ligado a la idea de nación misma, según Hooper-Greenhill, ante la caída de los metarelatos, que autentificaban y fortalecían la identidad nacional como fin teleológico de la sociedad y la historia, los sujetos tienen la capacidad de cuestionar la identidad nacional y por ende de complejizar esa idea. El museo en ese proceso debe ser partícipe al traer el pasado al presente y lograr cuestionarlo y reinterpretarlo.

El proceso acumulativo del conocimiento, el ideal de la objetividad en la historia, se debe cuestionar desde el museo como se cuestionó desde la historiografía durante gran parte del siglo XX, abriendo paso al revisionismo histórico (Novick, 1988), que más que un ciclo interminable de recuestionamiento de los temas ya abordados, permite la reinterpretación de supuestos que parecían inamovibles.

¿Qué papel juegan los casos analizados en la complejización y diversificación de la identidad nacional con respecto a la violencia como constructora de la misma? El Museo de la Policía y el Museo Militar poco hacen. Su concepción de transmisión de conocimiento es completamente moderna, sus exhibiciones atiborradas de elementos no buscan una experiencia sensible por parte del visitante sino la exhibición total del mayor número de objetos posibles de sus colecciones, o por lo menos eso parece. Como ya se mencionó la organización museográfica, está guiada por una especie de concepto de taxonomía de las armas o de los elementos de milicia. La interactividad es poca o nula y todo está dirigido a que el visitante, mediante la razón, asimile el proceso de la violencia como una idea lineal y simplificada de la misma, como ya se mencionó, de lucha entre el bien y el mal desde los inicios de la nación o incluso de la humanidad misma.

Por su parte la exposición iBasta ya!, teniendo en cuenta la emocionalidad como parte del proceso educativo, apela a ella en cuanto a que las imágenes, las historias y la reivindicación hacen parte de un proceso emocional que puede causar ciertas respuestas en los visitantes. Sin embargo, pese a que está como idea, nunca se llega a consolidar en la práctica, en gran medida por la capacidad de los colombianos para consumir imágenes violentas, reales o ficticias, en grandes cantidades. La exposición incluso intenta incrementar el tono cruel de las imágenes al mostrar degollados y cadáveres de los años 50 , junto con otras imágenes recurrentes, y ya exhibidas mediáticamente, de la violencia paramilitar o guerrillera. Aparte de ello, nada más en la exposición toca la sensibilidad del visitante. 
Eso para un joven de colegio, que ha crecido con escenas mucho más violentas que esas, no es más que lo mismo de siempre, pero en un museo. El punto es que no hay ningún tipo de reflexión sobre la vida del visitante, sobre su cotidianidad que lo haga reflexionar sobre los procesos de violencia en el país, el tema incluso se aleja del contexto de museo a nivel geográfico y temporal, al ubicar la violencia partidista como alejado en el pasado y la violencia reciente como un problema exclusivamente rural. ¿Qué pasaría si un adolecente se viera obligado a enterrar un bien preciado para él, o abandonarlo, o si se visualizara a sí mismo como desplazado? ¿No sería más provechoso que ver las imágenes de siempre en nuestros mediocres noticieros?

Unos meses antes, en el Archivo de Bogotá, a unas pocas calles del Claustro de San Agustín, del Museo Militar y del Museo de la Policía, un colectivo pequeño, denominado Mnemosyne, realizó una exposición en el hall del edificio sobre la UP, denominada El Sueño de la UP: Memorias de paz y democracia ${ }^{7}$. El proceso lo traigo a colación porque uno de los dispositivos museográficos, de manera sencilla, planteaba la idea de meter al visitante en el conflicto y en el rostro de las víctimas, en este caso de los militantes del partido de la UP que habían sido asesinados en los años 80 . Constaba de unos espejos con el rostro de algunas víctimas en marca de agua y el visitante al ver el espejo hacía parte de la muestra al reflejarse a sí mismo. Insisto que era algo sencillo pero que daba la oportunidad de una experiencia sensible al visitante, más que los textos o infografías que explicaban el proceso.

A los pocos días de cierre de la exposición iBasta ya!, otra exposición se abrió al público en el Claustro de San Agustín; Paisajes Ausentes, que estaba centrada en los procesos de exhumación de cadáveres de las víctimas de la violencia en Perú. La muestra fotográfica de Jonas Moller, es un buen ejemplo de como a través de la sensibilidad se pueden lograr procesos de aprendizaje, en este caso en un ejemplo paralelo (aunque no igual) de violencia. Las fotografias, como su nombre lo indica, hacían énfasis en la inmensidad del paisaje de las sierras peruanas (y algunos paisajes urbanos de Lima) con la soledad y, ausencia, como protagonistas. Algunas fotos mostraban rostros de niños, caminantes anónimos o niños sonrientes en su cotidianidad, la violencia no era protagonista, pero la ausencia que produce sí. Si bien la interactividad era poca, el énfasis en lo emocional del conflicto, en una especie de sentimiento sublime pero triste, podía ser mejor herramienta de aprendizaje que la sistematización de fotografías de la violencia.

Con los anteriores ejemplos, sencillos, solo me permito plantear que la violencia, en relación con la nueva condición del sujeto, como conjunto de emociones-racionalidad, puede ser aprovechada para fomentar procesos pedagógicos más fuertes en los visitantes, sobre todo en el público escolar, y así mismo complejizar el papel de dichos usuarios en la violencia y en la construcción de nación, y por qué no, lograr cuestionar la idea de nación misma al mostrar el conflicto como un problema más allá de las fronteras y más cercano a mis vivencias locales.

\section{Conclusión}

A través de estos ejemplos de la museología colombiana (que no la resumen pero la diagnostican) se puede ver que el conflicto no tiene una representación única en el museo y depende en gran medida del punto de vista que el museo quiera abordar. Esto se debe asimilar, y se puede problematizar, si se tiene en cuenta el contexto actual de Colombia, en el cual es fantasioso y engañoso situarnos en un posconflicto, en este sentido las visiones que se hagan

\footnotetext{
7 La exposición fue financiada por medio de una beca del Programa de Estímulos del Ministerio de Cultura y conto con el apoyo de la Centro de Memoria y del Archivo de Bogotá.

8 La muestra fue curada por una estudiante de la Maestría en Museología y Gestión del Patrimonio y el fotógrafo bajo la asesoría de la Dirección de Museos y Patrimonio Cultural de la Universidad Nacional.
} 
del conflicto, las narraciones que se hacen desde el museo, deben hacerse desde el supuesto de que el conflicto es actual, no se termina, sino que muta y se transforma.

Es necesario, para el museo, poner su mira en las causas del conflicto e intentar explicarlas a los nuevos ciudadanos, desde la emocionalidad, desde las nuevas teorías de transmisión del conocimiento, y sobre todo desde su contexto y sus necesidades. Si bien es cierto que muchas reflexiones artísticas son válidas a la hora de pensar y repensar el conflicto armado, también es cierto que el museo debe empezar a abrir las puertas a los estudios académicos que han investigado de manera ardua la violencia. En este sentido el iBasta ya! es un adelanto, sin embargo estas "traducciones" de los trabajos académicos a proyectos museográficos no se pueden hacer de manera tan simplificada, es el papel de los museólogos, como gremio en ascenso, crear herramientas que logren poner en exposición, al alcance del público, las investigaciones que señalan las causas reales de la violencia, para dar a los ciudadanos herramientas que les permitan la reconstrucción de este país. Esta traducción, volviendo a Greenhill, debe hacerse desde el concepto del posmuseo, desde la complejidad de los sujetos posmodernos y su forma de adquirir conocimiento, desde lo vivencial. ¿Por qué no mirar otras disciplinas como la publicidad o el diseño industrial, donde las nuevas formas de comunicar a través del diseño de experiencias, plantean formas de aprehender desde la inmersión sensorial antes que la intelectual?

Las herramientas pueden ser muchas siempre que la mirada sea cada vez más crítica para que se sobrepasen los elogios de los cocteles de inauguración o el respeto ingenuo de las jerarquías y los colegas. La crítica museológica como herramienta es la única manera de hacer que dicha disciplina en Colombia asuma uno de sus más grandes retos; la construcción del conflicto en Colombia como una problemática que atañe a todos y por ende la construcción de un nuevo paradigma en la museología.

\section{Bibliografía}

\section{Brown Goode, George}

1895 Between science and art: museums and development and anthropology.

1895 "The relationship and responsabilities of museums". Science 2 (New series): 111-124.

Deloche, Bernard

2002 El museo virtual. España: TREA.

Déotte, Jean-Louis

1998 Catastrofe y olvido, Las ruinas, Europa, el museo. Chile: Cuarto Propio.

Falk, John y Dieking, Lynn D.

2004 The contextual model of learning. En: Gail Anderson. Reinventig the museum. Gail Anderson (ed.): 139-142. Estados Unidos. Altamira Press.

Henderson, James

1984 Cuando Colombia se desangró. Bogotá: Ancora Editores.
Hooper-Greenhill, Eilean

2007 Education, pomodernity and the museum. En: Museum Revolutions: How museums change and are changed. Simon J. Knell, Suzanne MacLeod, Sheila Watson. (ed.): 367-377. Londres. Taylor \& Francis.

ICOM. Consejo Internacional de Museos http://icom.museum/L1/ (Consulta: 23 de abril 2014).

Morales, Luis Gerardo

1999 "Museo y grafía: observación y lectura de los objetos" Historia y grafia, 13: 225-253.

Novick, Peter

1988 That noble dream. U.K.: Cambridge University Press. 


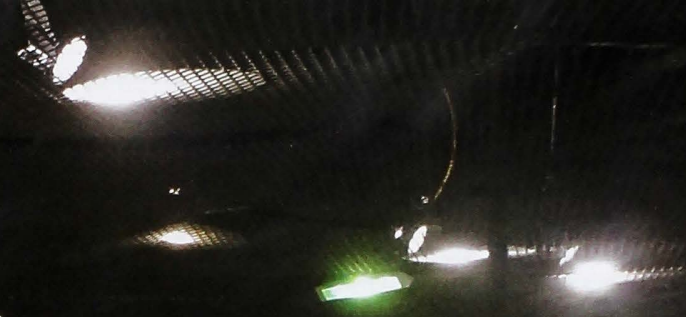

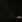
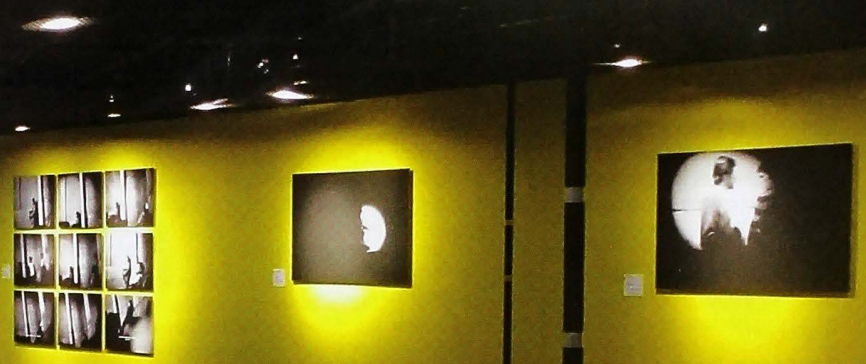

\section{bi}

